\title{
ENTREVISTA COM TALITA GUIMARÃES SALES RIBEIRO
}

\author{
Janailton Mick Vitor da Silva 1 \\ -1Universidade de Brasília, Brasília, Distrito Federal, Brasil
}

Talita Guimarães Sales Ribeiro cursou Letras-Tradução Inglês na Universidade de Brasília (UnB) de 2002 a 2006. Sua carreira em tradução começou a partir de um estágio na Embaixada Britânica em Brasília em 2005. Posteriormente, foi contratada para desenvolver atividades de consultoria em tradução e organização de eventos. No mesmo ano, começou a trabalhar para a empresa Deluxe Digital Studios, a princípio na revisão de legendas e depois na tradução. Ao completar 10 anos de carreira na área de legendagem, foi sondada por três outras empresas da área e passou a trabalhar para mais duas, a Visual Data e a Point 360. Além de tradutora, Talita é servidora pública concursada desde 2009 na UnB. Nesta universidade, já foi coordenadora de intercâmbio com a América do Norte, Ásia e Oceania na Assessoria Internacional da UnB e, desde 2013, tem trabalhado diretamente na área de revisão de livros para a Editora UnB.

Na entrevista concedida a Cadernos de Tradução, Talita Ribeiro nos fornece um panorama sobre seu ofício de tradutora audiovisual ao longo dos seus 13 anos de experiência, respondendo a perguntas sobre aspectos positivos e negativos da legendagem, estilo de tradução, visibilidade do tradutor, relação empresa-tradutor-cliente e processo de legendagem. Entre as respostas fornecidas, destacam-se alguns fatos importantes. A tradutora afirma que limitações técnicas da legendagem, registros linguísticos e condições de produção das legendas impõem certos desafios ao seu trabalho. Pon- 
tua ainda que o tradutor pode deixar uma impressão digital nas legendas que produz e, no seu caso, ela se faz visível, entre outros feitos, a partir do uso da norma culta escrita da Língua Portuguesa, o que pode ser interpretado como parte de seu estilo pessoal.

Cadernos de Tradução (CT): O que você entende por tradução?

Talita Guimarães Sales Ribeiro (TGSR): Esta pergunta é bem abrangente e eu teria de discorrer sobre a teoria da tradução para respondê-la. Especificamente no âmbito da tradução de legendas, eu diria que é a produção de um texto a partir de um texto em outro idioma, com o objetivo de transmitir, da maneira mais aproximada possível, o conteúdo e a forma do texto de partida.

(CT): Conte-nos um pouco sobre a sua atuação profissional.

(TGSR): Em 2005, comecei a trabalhar para a empresa Deluxe Digital Studios, a princípio revisando legendas, depois traduzindo. No mesmo ano, iniciei um estágio na Embaixada Britânica em Brasília, que acabou se tornando um contrato de consultoria em tradução e organização de eventos que durou até 2008. Em 2009, passei em um concurso para revisor de textos e retornei à Universidade de Brasília, agora como servidora. Em 2012, concluí uma pós-graduação lato sensu em revisão de textos, enquanto trabalhava na Assessoria Internacional da UnB como coordenadora de intercâmbio com América do Norte, Ásia e Oceania. Em 2013, pedi transferência para a Editora UnB para trabalhar diretamente na área de revisão de livros, e é onde me encontro ainda hoje. Em 2015, ao completar 10 anos de carreira na área de legendagem, fui sondada por três outras empresas da área e passei a trabalhar para mais duas: Visual Data e Point 360. 
(CT): Há quanto tempo trabalha como legendista e que tipo de trabalhos você já fez?

(TGSR): Há cerca de 13 anos. Já fiz tradução (origination), tradução de sound cues, revisão (proofreading / quality assessment), criação (inclusive tempos de entrada e saída), conform (ajuste de sincronia de legenda pronta), rematch (inserção de legenda já traduzida ao novo formato de arquivo, com sincronização), quality control, consistency check e avaliação de novos legendistas.

(CT): No caso das empresas de legendagem que você citou, elas têm alguns clientes específicos? Se sim, você já traduziu elou ainda traduz para quais deles?

(TGSR): Antes de mais nada, essas são empresas que intermedeiam o acesso das produtoras cinematográficas aos tradutores. Sim, essas empresas têm clientes específicos, e já fiz e ainda faço trabalhos para a Netflix, HBO, Warner Channel, Disney e Universal Studios.

(CT): Como se dá o seu relacionamento com esses clientes e essas empresas em termos de prazos, contrato(s), método(s), tipo(s) de produto(s) audiovisual(is), entre outras questões?

(TGSR): Os prazos são definidos pelo coordenador de cada projeto ao enviar o trabalho. Pode haver certa margem de negociação, mas, em geral, são curtos. Os contratos são assinados uma vez com cada empresa, no início da colaboração, como freelancer. O contrato é abrangente e em geral transfere os direitos autorais do trabalho do tradutor para a empresa de tradução. A metodologia é definida pelas empresas por meio de manuais e treinamentos. Elas também oferecem as ferramentas necessárias, como softwares. Atualmente, o software padrão é web-based e faz parte de uma plataforma chamada Sfera Labs. 
(CT): A respeito da metodologia de trabalho, você poderia citar os passos seguidos na legendagem dos seus trabalhos?

(TGSR): Primeiro, a empresa me envia uma oferta de um trabalho, com a descrição do tipo de atividade, o nome do filme/seriado, o tamanho em número de minutos e o prazo. Depois, eu aceito ou rejeito a oferta. Em seguida, os arquivos, já transcritos no idioma de partida, divididos em caixas de legendas e sincronizados, são disponibilizados no meu login nos sites das empresas. Então eu faço a tradução, se for essa a tarefa, e realizo os procedimentos de verificação de ortografia, sintaxe e vídeo. Após enviado, o arquivo é disponibilizado para um revisor. Se a minha tarefa for a revisão, eu realizo os mesmos procedimentos já realizados pelo tradutor, verificação de ortografia, sintaxe e vídeo. Depois de o arquivo ser entregue pelo revisor, ele pode ser enviado para um segundo revisor. Esse estágio depende do cliente e do prazo. O arquivo volta a ser disponibilizado para mim (tradutor), que faço uma análise de cada sugestão feita pelo(s) revisor(es) e as aceito ou rejeito, uma a uma. Nesta etapa, que chamamos de acceptance stage, é que incluo meu nome no final das legendas. O arquivo é então finalizado e enviado para um controle de qualidade (quality control) na própria sede da empresa. Caso seja necessário, a equipe de controle de qualidade me envia questionamentos ou pedidos de alterações. Por fim, o arquivo é finalizado e enviado para o cliente.

(CT): Você afirmou acima que o revisor é uma figura bem proeminente na legendagem. Você já observou se suas legendas foram alteradas no produto publicado?

(TGSR): Nunca observei isso em legendas que eu traduzi. Já notei apenas ocasiões em que sugestões que fiz como revisora não foram aceitas. 
(CT): Há algum tipo de guia que você usa para padronizar algum aspecto da legendagem? Se sim, é uma iniciativa sua ou uma condição do(s) cliente(s)?

(TGSR): Sim. Há guias de cada empresa de legendagem e guias específicos dos estúdios produtores dos filmes e seriados, e todos eles devem ser seguidos (a exemplo dos guias da Netflix (NETFLIX, 2018a; 2018b).

(CT): De modo geral, quais são os aspectos positivos e negativos de legendar uma obra audiovisual?

(TGSR): Os aspectos positivos são muitos. Para começar, o material é interessante, o que torna tudo mais prazeroso, além de os textos serem de estilos variados. Claro, nessa área, a tradução linguística é facilitada pelo componente visual, pois as imagens ajudam a compreender o que os personagens dizem. A predominância da oralidade também é um facilitador, porque a língua falada tende a incluir menos termos de difícil acesso, o que diminui a necessidade de pesquisas durante o processo tradutório

Quanto aos aspectos negativos, a primeira dificuldade tem a ver com as limitações impostas pela legendagem. Há mais limitações do que uma tradução normal, pois é preciso lidar com a razão caracteres/tempo. Eu mencionei a oralidade como um facilitador, mas ela traz também problemas, pois o texto fonte é oral, mas deve ser transformado em texto escrito, o que traz uma série de dúvidas a respeito das regras gramaticais que em geral não são utilizadas na fala. Ou seja, será que posso usar "tá", um "namorar com" etc.? Posso iniciar a fala com um pronome, como fazemos na língua oral? Posso alternar entre a segunda e terceira pessoas do singular, como fazemos ao usar "eu te amo" e "você é meu melhor amigo", característica do português brasileiro falado? 
(CT): Quais são as suas maiores dificuldades e desafios na tradução de legendas?

(TGSR): Eu diria que o tradutor que atua nessa área tem que estar atento a limitações relacionadas ao espaço para texto (número de caracteres) e ao tempo de legenda (razão entre número de caracteres e o tempo da legenda no ar). Em ambos os casos, nem sempre há espaço e tempo suficientes. Além disso, questões relacionadas à informalidade são desafiadoras, como mencionei na questão anterior. É preciso se atentar ao uso de regionalismos e gírias no idioma de origem, e como traduzi-los. O pouco prazo para a tradução também adiciona certa complexidade, principalmente quando se trata de obras que ocasionalmente trazem terminologias muito específicas, como programas médicos ou de procedimentos de perícia forense. Por fim, outra dificuldade é a fala quebrada, incompleta, repetitiva e às vezes sem sentido em legendas sem roteiro (como comentários do diretor e making of em geral).

(CT): Diante dos aspectos e das dificuldades acima mencionados, você acredita ser possível deixar uma marca pessoal, sinais de um estilo seu de traduzir nas suas legendas?

(TGSR): Acredito que toda tradução é uma criação e, assim, carrega uma marca do seu "criador". Certamente minhas legendas têm características consistentes com o meu histórico e experiência. Por exemplo, tenho um passado de tradução em ambientes muito formais, como embaixadas e, dentro do razoável, vejo que mantenho certas regras da gramática normativa que usamos pouco no discurso oral, como o uso do "lhe". Percebo que alguns legendistas escolhem se aproximar o máximo possível da linguagem coloquial. Meu estilo é mais intermediário entre o coloquial e o formal. 
(CT): Você afirmou acima que "toda tradução é uma criação" $e$ que o tradutor (no nosso caso, ola legendista), é um "criador". Sendo assim, você acredita que ola legendista é um(a) tradutor(a) visível ou invisível na tradução de legendas?

(TGSR): O legendista é um tradutor visível. Acho que a legenda é uma das formas de tradução que expõe mais o tradutor. Na tradução técnica ou científica, por exemplo, o conteúdo costuma ser mais rígido, e assim o tradutor (em geral) trabalha com menos possibilidades de variações. No meio literário, quando se traduz um livro de literatura, grande parte dos leitores-alvos só terão acesso à obra traduzida, o que não é o caso da legendagem. Aqui, as variáveis são muitas, uma vez que o material envolve gírias, coloquialismos, expressões idiomáticas etc., e o público está exposto ao texto original ao mesmo tempo em que vê a tradução. Ou seja, as escolhas do tradutor ficam mais visíveis ao público em geral.

(CT): Por fim, Talita, você lida com algum tipo de questão sociocultural, política elou linguística na legendagem que você julga interessante mencionar?

(TGSR): Certamente muitas. Vou dar exemplo de apenas uma. Não tenho o costume de usar palavrões como parte do meu vocabulário, mas eles são muito presentes nas legendas. Tenho de me policiar para não "atenuar" os palavrões, só por eles me parecem agressivos demais. Há alguns anos, uma das empresas para as quais trabalho estabeleceu uma equivalência entre os palavrões em inglês e português para garantir certa consistência nas traduções, uso esse guia como base. 


\section{Referências}

NETFLIX. Timed text style guide: general requirements. Scotts Valley: Netflix, 2018a. Disponível em: <https://backlothelp.netflix.com/hc/en-us/ articles/215758617-Timed-Text-Style-Guide-General-Requirements > . Acesso em: 12 mar. 2018.

Brazilian Portuguese timed text style guide. Scotts Valley: Netflix, 2018b. Disponível em: <https://backlothelp.netflix.com/hc/en-us/articles/215600497Brazilian-Portuguese-Timed-Text-Style-Guide > . Acesso em: 12 mar. 2018.

Recebido em: 03/04/2018 Aceito em: 07/06/2018 Publicado em setembro de 2018 